\title{
FECUNDITY OF CUTTLEFISH (SEPIA OFFICINALIS) DETERMINED FROM LABORATORY EGG LAYING: IMPLICATIONS FOR FISHERIES MANAGEMENT
}

\author{
Howaida R. Gabr \\ Marine Science Department, Suez Canal Univ, Ismailia, Egypt
}

Key words: Cephalopods, S. officinalis, actual and potential fecundity.

\begin{abstract}
Current method of estimating fecundity of Sepia officinalis is based $C_{\text {on }}$ the number of laid eggs as actually observed. Data account of prolonged spawning in $S$. officinalis of this study were primarily based on observation of different-sized females reared from hatching. At the end of the experiment, the animals were dissected to check the maturation stage of the gonads and the presence of ova and their developmental stage. The effective and potential fecundity were estimated. Fecundity of $S$. officinalis was over most of the suggested fecundity for wild females, yet over the suggsted fecundity for captive animals. Potential fecundity estimates ranged from 5000 to 6000 at $140 \mathrm{~mm}$ mantle length and 1000 to 2000 at $120 \mathrm{~mm} \mathrm{ML}$. Batch size ranged from 5 to 46 batches. Spawning lasted from 25 to 165 days and the average time elapsed between batches was 1.6 to 7.35 days. The number of oocytes destined to be matured in a season is decided prior to spawning and can be identified and counted before release of the first egg batch. An accurate estimate of these eggs should be at the beginning and end of the spawning, and their difference is considered to be the actual fecundity. All eggs $<2.0$ $\mathrm{mm}$ diameter were considered potentially capable of being spawned. An attempt at improving scientific fishery management policy is made. The considerable benefits accruing from the laboratory behavior observations are described. These benefits would contribute towards the projecting future developments in commercial cuttlefish aquaculture particularly its breeding stage.
\end{abstract}

\section{INTRODUCTION}

Fecundity estimates for cuttlefish involve many difficulties, such as determining which ovarian eggs to count, judging the appropriate times in the breeding cycle to take samples, and 
estimating the number of batches spawned. For these reasons, there was a wide range in estimating fecundity between different authors even though published works on the fecundity of cuttlefish are few.

Because cuttlefish release many batches of eggs (Boletzky, 1975 \& 1987), counting only the ripe eggs would give a grossly low estimate. The presence of eggs of various sizes and stages usually indicates a prolonged spawning period during which new eggs may be produced and others have the time to develop. In this latter case, egg counts at any one time may be very misleading (Voss, 1983). Mangold-Wirz (1963) reported that female Sepia officinalis may lay from about 200 to 550 eggs depending on its size, which may vary from 110 to $250 \mathrm{~mm}$ ML. Richard (1971) estimated similar number (150 to 500) for $S$. officinalis by counting mature ova only; Bakhayokho (1983) counted only large inaturing and mature ova. However, Boltezky (1975\&1987) predicted a fecundity value of 1000 to 2000 for a female of $200 \mathrm{~mm}$ ML from his count of actual numbers of ova laid plus all ovarian ova remaining after mortality of an individual female.

Since a female organism under food stress may maintain reproductive output at the expense of somatic maintenance and hence longevity (Stearns, 1989; Kaitala, 1991) or reduce reproductive output, thereby maintaining life span (Spight \& Elmen, 1976; Ernsting \& Isaaks, 1991; Qian \& Chia, 1991); therefore, in this study, Sepia officinalis were maintained under condition of high food availability to provide the essential fecundity estimates. This study aimed to obtain estimates of the life-time fecundity of $S$. officinalis particularly with regard to rates, variation, and periodicity of egg production. This knowledge is an essential part of scientific fishery management policy. Furthermore, in view of the fact that there has been resurgence in worldwide interest in cephalopods aquaculture during the past few years, this study may add information and stimulation to biologists and culturists interested in cephalopods aquaculture.

\section{MATERIALS AND METHODS}

Cuttlefish used in this study were hatched from eggs that had been laid in the Marine Biological laboratory in Woods Hole, U. S. A. They were maintained from hatching until the end of their life cycle. Spawn was reared under natural daylight conditions. At 6 months age and about $100 \mathrm{~mm}$ mantle length (ML), 10 virgin females (non 
copulated females) were transferred to a large tank and maintained separately. At age of 9 months, when the animals were considered sexually mature, six females only survived, five of these females measured 140-150. mm ML, and one measured $120 \mathrm{~mm} \mathrm{ML}$. The length was the only measurement taken for these animals through the aquarium glass to keep handling and disturbances to a minimum. These six females were maintained individually within 6 tanks. To test the idea whether or not mating behavior might be one of the triggers for sexual maturation of female, one of these females was kept virgin and alone until death. For mating purpose, a male $S$. officinalis was introduced to the rest five females' tank only once per 3 weeks. After copulation, which generally started immediately, the animals were separated to avoid uncontrolled interaction that could stress the female under these confined conditions. After mating, female cuttlefish store sperm in seminal receptacles to be used for fertilization of eggs immediately prior to spawning (Mangold, 1987).

\section{Maintenance system and rearing condition}

Each rearing tank measured $135 \mathrm{~cm}$. in length, $75 \mathrm{~cm}$. across (width) and $36 \mathrm{~cm}$. depth. The water quality was favorable throughout the experiment. Temperature was kept between 19.0 $21.0^{\circ} \mathrm{C}$. Salinity ranged from $30.0 \mathrm{ppt}-32.0 \mathrm{ppt}$. The $\mathrm{pH}$ varied from $7.8-8.2$.

\section{Feeding}

Palaemonid shrimps and Artemia were added when cuttlefish were juvenile. Fry fish were added after one month. After 2 months, frozen specimens of shrimp were given, using a feeding bar. When cuttlefish were accustomed to feeding on dead fish, the frozen fish were tossed directly into the tank twice a day. The studied Females continued to feed at high rate $(=3$ per day) until death or close to death.

\section{Eggs collection and processing}

Data regarding reproductive output were collected from the six females from first day of laying eggs until the last one died during a period of 165 days from November 14, 1997 to May 1, 1998. Spawning was determined from a different number of egg laying events, each resulting in a batch of eggs. Tanks were checked daily for eggs that were counted regularly in every batch. Plastic rubber bands were used to separate between batches. When eggs are 
recently laid, they were very soft and it was difficult to have consistent measurements. Therefore, eggs were separated for measurements on the day following laying. For every batch, representative sample of about 10-20 eggs were taken. The eggs were separated from their point of attachment then length and weight per egg were taken. During most of the experimental period, the animals were frequently observed daily, between 10 a.m. and 10 p.m., on most days.

Data obtained from counting eggs per batch, and measurements of eggs allowed the foliowing aggregated measures to be calculated for each female: 1-total number of eggs laid, 2-total wet weight of eggs laid, 3-maximum and minimum number of eggs laid in one batch, 4- average number of eggs laid per batch, 5maximum and minimum wet weight of eggs laid in one batch, 6average wet weight of eggs laid per batch, 7- average wet weight per egg (for each batch, the weight per egg was calculated; the average weight per egg is the average of this value taken over all batches laid), 8- number of batches laid, 9-Duration of laying in days (day I is the day the first egg batch was laid) and 10 -average time in days between batches (calculated by dividing the laying duration by the number of batches laid).

\section{Ova estimation and measurments}

The second length and weight were taken on dead females. To estimate the number of developing eggs remaining in the oviduct and ovary which were not shed, the ovaries were dissected free from the gonad and weighed. Ova in the proximal oviduct were estimated from fresh specimens, while those in the ovary were estimated from preserved ovaries (in 10\% formalin) using the total count of all maturing and mature ova. From the remaining part of the ovary (which contained only immature ova), one sample ranging from 0.1 to $0.25 \mathrm{~g}$ was removed. Subsamples of immature ova were counted and multiplied up to give the exact number for the whole ovary. The counting and measuring were carried out with a binocular dissecting microscope equipped with an ocular micrometer.

\section{RESULTS}

\section{Reproductive output characteristics}

Spawning in all the six femaies of Sepia officinalis was found to be continuous or intermittent. The females died within 1 to 3 days 
following the last laid batch. Features of these batches such as batch size and time between batches were variable within individual Sepia, yet varied between the six individuals (Table 1). The first five females measured 140-150 mm ML, while the sixth female measured $120 \mathrm{~mm}$ ML. The virgin female (female number 1) that was kept alone until death, laid relatively greater number of eggs, (3143 eggs in 29 batches) over the course of 65 days which is an average of 108.38 eggs every 2.10 days. Among the females whose copulated with a male on a regular basis every 3 weeks, was female number 2 which laid the greatest number of eggs ( 4265 eggs in 46 batches) over the longest course of 165 days, an average 92.72 eggs every 3.61 days. Female number 3 laid 1245 eggs in 15 batches over the shortest course of 25 days, an average 83 eggs every 1.6 days. Females number 4 and 5 produced the smallest number of eggs $(523$ and 569 eggs respectively). Female number 4 produced 5 batches over the course of 31 days period, an average 104.6 eggs every 6 days. Female number 5 laid 9 batches over the course of 30 days, an average 63.22 eggs every 3.20 days. Surprisingly, the smallest female (female number 6) laid 1464 eggs in 20 batches over a relatively long course of 148 days, an average 73.20 eggs every 7.35 days.

It was noticed that females number 3,4 and 5 suffered some damage caused by rough treatment during male mating activity; their skin damage did not completely heals and it is possible that this is the reason for their early death. It was appeared that these animals are fully sexually mature. Meanwhile, females number 1,2 and 6 which died after a lengthy period were found to be in a spent stage, and it seems probable that death in these cases was due to endogenous factors rather than physical conditions.

\section{Batch sixe}

Each captive female produced egg batches of different sizes and different weights over the course of its reproductive life (Fig. 1). The minimum number of eggs (12 eggs) per batch was estimated for female number 6.They had a weight of $8.02 \mathrm{gm}$, The maximum number of eggs per batch (375 eggs) was estimated for the virgin female (female number 1), showing a weight of $209.76 \mathrm{gm}$. Within the individual, there was no significant correlation between number of eggs laid per batch and duration of laying (linear regression, $\mathrm{p}<0.5$ ). 


\section{Egg size}

Egg size was indicated as wet weight, since it is a more reliable measure than egg length. A tendency of increasing egg size with increasing adult size was observed (Table 1). Of six females, the smallest female (female number 6 ) laid relatively smaller eggs in all batches with a mean weight of $0.67 \pm 0.05$, with a maximal egg weight of 0.86 and a minimal egg weight of 0.59 . On the other hand the mean egg weight measured in 5 females of approximately equal size was $0.89 \pm 0.24 \mathrm{gm}$. with a maximal egg weight of $1.36 \mathrm{gm}$. and a minimal egg weight of $0.53 \mathrm{gm}$. Fernale number 3 showed a marked smaller size of eggs in its last two batches that lead to smaller average of wet weight per egg (Table 1).

\section{Ovarian characteristic}

Ovaries of six females were examined after death to determine the size frequency distribution of ova. This distribution revealed three maturity stages : relatively mature ova larger than $5 \mathrm{~mm}$ major axis (smooth ova) ; maturing ova $3-5 \mathrm{~mm}$ (with striation of follicle cells); and immature ova smaller than $2 \mathrm{~mm}$ (without striation of follicle cells).

Although of virgin female (Female 1) laid relatively a high number of eggs (3143), it had a relatively high number of ova (2113 ova) with a distinct mode in the smallest size class (Figure 2). All females that had short spawning time and laid small number of eggs (females number 3, 4, and 5) appeared to have ovaries with similar ova size-class distributions and have large number of ova (3953, 3565 , and 3945 ova respectively). All exhibited a pattern of a decreasing number of ova from the smallest to the largest size class, with a distinct mode in the smallest size class. The minimum number of ova ( 220 \& 121 ova) was estimated in females number 2 \& 6 respectively that had the longest spawning period and laid relatively greater number of eggs. The pattern of ova size in these two females did not show distinct mode in any of the size classes.

All six females were examined for reproductive indices that are measures of reproductive effort. The mean ovary index (ovary wet Wt: total body weight including ovary) was $0.04 \% \pm 0.02$, an average of $0.02 \%$ for female no. 6 to $0.06 \%$ for female no. 1 . The mean nidamental gland index (nidamental wet $W t$ : total body weight including nidamental gland) was $8.35 \% 3.06$. This index was markedly skewed towards the highest index (13.07\%) in female that laid highest number of eggs and had longest spawning period (female 
no.2) and lowest index (4.82\%) in female that laid smallest number of eggs and had short spawning period (female no. 4).

\section{Reproductive observation}

Mating activity was observed in detail. The male always attempted direct copulation as soon as it encountered a female. No color changes or other signs of preliminary courtship were noted. Head-to-head mating position was observed. Copulations were always long, lasting for approximately $7-20 \mathrm{~min}$. This behavior has been described previously in detail (Hanlon et.al., 1999; Hanlon\& Messenger,1996). It was noted that when a male was first introduced to female's tank, in 5 minutes or less they will either accept each other or start to tear each other apart. Sometimes the approached individual appears to frantically attempt to mate without giving the female chance to accept.

In observation on laying eggs, captive female attach eggs in groups on to an aeration tube inside the tank. We observed females laying at a rate of one egg approximately every 40 second. Batches of eggs were often deposited close to previously laid batches thus forming larger groups of eggs. Cuttlefish lay eggs during the daylight hours or at night. The process of egg laying can last for more than 4 hours. Hatching also can be in daylight or at night and the eggs usually take from 30 to 40 days to hatch at approximately $19^{\circ} \mathrm{C}$.

All of the laid eggs were fertile except those laid by virgin female number 1 and the last 2 batches of the small sized egg laid by females number 3 and 6.It was observed that egg fertiiity and survival rate of hatchilings do not appear to be affected by eggs size. All embroynic development proceeded normally and resulted in healthy young animals that measured 5 to $8 \mathrm{~mm} \mathrm{ML}$ at hatching. After one week, survival was not completely confirmed, since further observation ceased.

\section{DISCUSSION}

These results are meaningful in demonstrating the possibilities of fecundity variation as a function of adult survival and animal size. The most fecund female laid a greater number of eges simply because it survived for longer than the less fecund female or it has a larger size.Fecundity of Sepia officinalis seems over most of the suggested 
fecundity found in the wild, yet over the suggsted fecundity from captive animals.

Over a narrow' adult size range $(140-150 \mathrm{~mm} \mathrm{Ml})$. the greatest number of eggs laid by a female survived for nearly 6 months was 4265 eggs. This appears to be the maximum the female lays since the remaining ova were only 220 . By counting the actual number of ova laid, plus all ova remaining in the ovary following mortality, the potential fecundity for this female was approximately 4485 . The second female in survival lived for about 2 months and laid 3143 eggs and had a potential fecundity of 5256 . The other two females survived for about 30 day and laid 550 eggs only. The exception was the female that survived for only 25 day but laid little higher eggs (1245 eggs). The wide range of ova size present in these three females indicated that the potential fecundity remained well above the effective fecundity (the actual number of laid eggs). Their potential fecundity was in range of 4000-5500. Fecundity differed markedly with the animal size. The smallest female of $120 \mathrm{~mm} \mathrm{ML} \mathrm{survived}$ more than the previous female for 148 day but laid only 1465 , and its potential fecundity was 1600 .

The exact timing of sampling is likely to be the most critical factor influencing the accuracy of fecundity determination for wild cuttlefish. An accurate estimate of fecundity can be determined at the commencement of spawning to estimate potential fecundity, by counting all the ova including the one that are less than $2 \mathrm{~mm}$, and at the end of the season to estimate the number of developing ova remaining in the ovary which were not shed. The difference between the two numbers represents the actual fecundity. With the foregoing information, it is plausible to predict that effective fecundity between 5000 and 6000 are perfectly conceivable for large-sized individuals of Sepia officinalis measuring nearly 140-150 mm ML and 1000-2000 is perfect for small - sized females measuring nearly $120 \mathrm{~mm} \mathrm{ML}$. This number is about five times fecundity predicted by Boletzky (1975, 1987) for a female of $20 \mathrm{~mm} \mathrm{ML}$ lived for 4 months and greatly exceed the numbers suggested by (Manglod-Wirz,1963; Richard, 1971; Bakhayokho, 1983; Gabr et al,1998) for wild animals.

This study does reconfirm the evidence of Boletzky (1987) indicating that Sepia officinalis is capable of producing multiple egg batches over long intermittent spawning with periods of inactivity as long as 2 weeks, to virtually continuous chronic spwawning over many weeks. 
The present laboratory observations do not actually support the idea that mating behavior might be one of the triggers for sexual maturation of females (Ikeda et al.,1993).During our experiments, one of the females laid high number of eggs without copulation; so mating is not necessary as trigger on the onset of the female yolk formation. The endocrine and nervous control mechanisms of reproduction are complicated (Hanlon \& Messenger 1996).

It is likely that there would be sufficient time for any vitellogenic ova (potential annual fecundity) to mature if the animal had survived and one can hypothesize that vitellogenic ova take about 150-180 days to grow to full size. Several lines of evidence support this contention: (1) the number of vitellogenic ova declines with increasing spawning period as it was clear by ovarian size distribution (Fig. 2); 2- size distribution of ovarian ova of most the survived animals were in different maturity stages and not only in the early stages of yolk development, this means that complete maturation or production of previtellogenic oocytes occurs during the spawning and over an extended period; (3) some females spawns over an extended period more than 5 months, and (4) the extended spawning period was confirmed also on wild animals (Bakhayokho, 1983; Boletzky, 1983; Le Goff and Daguzan, 1991; Gauvrit et al., 1997). In light of these observations, the intriguing question "do all the ova produced in the female ovaries reach maturity?" could be answered.

In nature, a female survives to spawn over a period of time sufficiently long to allow complete maturation of all the potentially available ova depending on various factors including the availability of appropriate food to counteract exhaustion (Boletzky, 1987). However, our laboratory observations indicated that possible causes of the "failure" of Sepia officinalis to survive and complete maturation of all immature ova include two major reasons. First, development of skin lesions that resulted from heavy mating activity and the aggressive behavior of the male. These lesions could be possibly linked to failure of the immune system, which might have lead to ultimate cause of mortality. The extensive skin lesions can heal in the sea, but in the aquarium skin damage rarely heals and any animal with such abrasions will rarely live for more than a few days (Boyle, 1981).The behavior of the male if not carefully controlled often results in injured female. This problem is probably one of the most important aspects of whether or not breeding cuttlefish will be successful. If the brood stocks are not healthy then they will not be able to survive and give good numbers and quality of eggs. Housing 
a male in brood stock' tank during spawning might be a better option than introducing a male to a female suddenly. Placing the two together might help to slow down the initial instinctive aggressive behavior and they might feel that they are compatible and not view each other as aggressive rivals so they can pair up by themselves; on other way aggression from male can cause the female to become very stressed and more prone to disease. Future experimental testing is required to evaluate this hypothesis.

Second, an interesting difference was observed in nidamental gland of exhausted females (females spawn over long period) in this experiment: The left gland (the one next to oviducal gland) of these females were increased greatly in size in compare with the right gland with clear red pigmentation, whereas those of animals that died early were having remarked smaller size with no difference in size between the two gland and were pale whitish without any pigmentation. This variation was reflected by the difference in nidamental gland index. Indeed, it appears that this species is capable of meeting the demands of oocyte production. without metabolizing reserves of other tissues. This may be because they continued to feed during the brooding period, fasting only briefly before death. All the six females died in good condition; thus energy for gonad production is diverted primarily from the food supply. Thus, mortality in Sepia officinalis might be due to reproductive failure initiated by loss of the nidamental gland function and halting the process of oocyte maturation. But at this point, we must be careful in analyzing our findings, since the present results were obtained from cuttlefish maintained in the aquarium. The changing in the nidamental gland of this species after spawning should be the subject of future study in lab and nature. These results agree with some studies on $S$. pharaonis (Gabr et.al., 1999). This study demonstrate that senescence in female Sepia pharaonis are not due to metabolism of body protein for oocyte production but are most likely due to metabolic changes that occur after the spawning of the animal. Studies on Loligo forbesi (Collins et al., 1995), L. gahi (Guerra \& Castro, 1994), Illex argentinus (Hatfield et al., 1992; Rodhouse \& Hatfield, 1992; Clarke et al., 1994) and Photololigo sp.(Moltschaniwskyj, 1995)have also indicated that maturation and growth occur simultaneously during most of the life cycle and the condition of the squid remains high at maturation. 


\section{REFERENCES}

Bakhayokho,M.(1983). Biology of the cuttlefish Sepia officinalis hierredda off the Sengalese coast. In : "Advances in Assessment of World Cephalopod Resource "J. P.Caddy (Editor). FAO Fish.Tech.Pap., 231: 204-263.

Boletzky, S.V. (1975). The reproductive cycle of Sepiolidae (Mollusca, Cephalopoda). Pubble. Staz. Zool. Napoli., 39: 84-95.

Boletzky, S.V. 1983. Sepia officinalis. P. 31-52. In : "Cephalopod Life Cycles" P.R. Boyle (Editor)". Vol. 1. Acadamic Press, London. 475 pp.

Boletzky,S.V.(1987). Fecundity variationin relation to intermittent or chronic spawningin the cuttlefish, Sepia officinalis L. (Mollusca, Cephalopoda). Bull. Mar. Sci., 40(2): 382- 387.

Boyle,P.R.(1981).Methods for the aquarium maintenance of the common Octopus of British waters, Eledone cirrhosa. Laboratory Animals., 15: 327-331.

Clarke, A.,Rodhouse.P. G and Gore.D.J.(1994). Biochemical composition in relation to the energetics of growth and sexual maturation in the ommastrephid squid Illex argentinus. Phil. Trans. R. Soc. Lond.,344: 201212.

Collins,M.A.; Burnell, G. M. and Rodhouse. P. G. (1995). Reproductive strategies of male and female Loligo forbesi (Cephalopoda: Loliginidae). J. Mar. Biol. Ass. U.K., 75: 621-634.

Ensting, G. and Isaaks. J.A.(1991).Accelerated ageing: a cost of reproduction in carabid beetle notiophilus biguttatus. F. funct. Ecol., $5: 299-303$. 
Gabr, H. R.; Hanlon. R. T.; Hanafy,M. H. and El-Etreby, S. G. (1998). Maturation, fecundity and seasonality of reproduction of two commercially valuable cuttlefish, Sepia pharaonis and $S$. dollfusi, in the Suez Canal. Fish. Res., 36: 99-115.

Gabr, H.R.;Hanlon, R. T.; Hanafy, M. H. and El-Etreby, S. G. (1999).Reproductive versus somatic tissue growth during the life cycle of the cuttlefish Sepia pharaonis Ehrenberg (1831). Fish. Bull., 97 (4):

Gauvrit,E.;Le Goff, R. and Daguzan, J.(1997). Reproductive cycle of the cuttlefish, Sepia officinalis (L.) in the northern part of theBay of Biscay. J. Moll. Stud., 63 (1): 19-28.

Guerra, A. and Castro. B. G. (1994). Reproductive-somatic relationships in Loligo gahi (Cephalopoda: Loliginidae) from the Falkland Islands. Antarctic Sci., $6: 175-178$.

Hanlon,R.T. and Messenger, J. B. (1996). "Cephalopod Behavior". Cambridge University Press.

Hanlon,R.T.; Ament, S. A. and Gabr. H.R.(1999). Behavioral aspects of sperm competition in cuttlefish, Sepia officinalis (Sepioidea: Cephalopoda). Mar. Biol., 134 (4)719-728

Hatfield, E. M. C.;Rodhouse, P. G. and Barber, D. L.(1992). Production of soma and gonad in maturing female Illex argentinus (Mollusca: Cephalopoda). J. Mar. Biol. Ass. U.K., $72: 281-291$.

Ikeda,y.; Sakurai,Y. and Shimazaki, K.(1993). Maturation process of the Japanese common squid Todarodes pacificus in captivity. In: "Recent Advances in Cephalopod fisheries biology". Okutani. T., O'Dor, R.K. and T. Kubodera,(eds.).Tokai University press: pp.179-187. 
Kaitala,A.(1991).Phenotypic plasticity in reproductive behaviour of water-striders: trade-offs between reproduction and longevity during food stress. Funct. Ecol, 5: 12-18.

Le Goff, R. and J. Daguzan. (1991). Growth and life cycles of the cuttlefish Sepia officinalis L. (Mollusca: Cephalopoda) in south Brittany (France). Bull .Mar. Sci.,49(1-2):341-348.

Mangold-Wirz, K.(1963). Biologie des cèphalopodes benthiques et nectoniques de la Mer Catalane. Vie Milieu. Supple., $13: 285 \mathrm{pp}$.

Mangold-Wirz, K.(1987). Cephalopod reproduction. P. 187200. In: "Cephalopod Life Cycles". P.R. Boyle (Editor) Vol. II, Comparative reviews. Academic Press, London.,441 p.

Moltschaniwskyj,N.A.(1995).Multiple spawning in the tropical squid Photololigo sp.: what is the cost in somatic growth? Mar. Biol., 124(1): 127-135.

Qian,P.Y., and Chia. F.S. (1991).Fecundity and egg size are mediated by food quality in the polychaete worm capitella sp. J. Exp. Mar. Biol. Ecol., 148:11-25.

Richard, A. (1971).Contribution a l etude experimentale de la croissance et de la maturation sexuelle de Sepia officinalis L.(Mollusque Cephalopode).Ph.D.Thesis. Sc. Nat., Univ. Lille.,264 pp.

Rodhouse,P.G. and Hatfield C. E. M. (1992). Production of soma and gonad in maturing male Illex argentinus (Mollusca : Cephalopoda).J.Mar. Biol. Ass. U.K., 72 :293-300.

Spight, T. M., and Elmen. J. (1976). Clutch sizes of two marine snails with a changing food supply. Ecology., 57: 1162-1178. 
Steams,S.C.(1989). Trade - offs in life history evolution. Funct. Ecol..3: 259-268.

Voss,G.L.(1983). A review of cephalopod fisheries biology. Mem. Nat. Mus. Vict., 64 : 229-241. 


\section{FECLNDIT OF CUTTLEFISH (SEPU OFFICHALIS) DETERAIINED FROM 113 LABORATORY EGG LAYTNG: IMPLICATIONS FOR FISHERIES

Table 1. DitTerent parmeters characteristing the reproductive ourput of 6 fensles of S. officinalis. observed under laboator conditions.

\begin{tabular}{|c|c|c|c|c|c|c|}
\hline Panmeters & Fomale1 & Fumb 2 & Fornate 3 & Female 4 & Fenale 5 & Fomale 5 \\
\hline Fernale weigh: (on) & 527 & 535 & 472 & 390 & 548 & 281 \\
\hline tolay number of eggs land & 3143 & 4255 & 1245 & 523 & $56 \theta$ & 1404 \\
\hline tolal weight of eggs laid & 2247.74 & 4669.68 & 698.54 & 352.07 & 471.83 & 074.38 \\
\hline maximum number of ogas laid in one batch & 375 & 320 & 335 & 233 & 150 & 120 \\
\hline minirnum number of oggs laid in one balch & 20 & 34 & 35 & 40 & 15 & 12 \\
\hline average number of oggs laid / batch & 108.38 & 02.72 & 83.00 & 104.60 & 63.22 & 73.20 \\
\hline maximum wet wright of egas laid in one batch & 209.78 & 283.33 & 223.33 & 142.30 & 135.00 & 80.50 \\
\hline mininum wet weight of egos laid in one batch & 14.60 & 37.40 & 10.36 & 32.40 & 14.05 & 8.02 \\
\hline avarage wat weight of oggs laid / balch & 77.51 & 101.51 & 48.57 & 70.41 & 52.40 & 40.71 \\
\hline average wet weight per ogg & 0.73 & 1.12 & 0.60 & 0.71 & 0.84 & 0.87 \\
\hline batch number & 29 & 40 & 15 & 5 & 9 & 20 \\
\hline duration(length of laying eggs time) & 65 & 165 & 25 & 31 & 30 & 948 \\
\hline average tima betwen batches (in days) & $2 . t 0$ & 3.81 & 1.60 & 6.00 & 3.20 & 7.35 \\
\hline
\end{tabular}


Fl

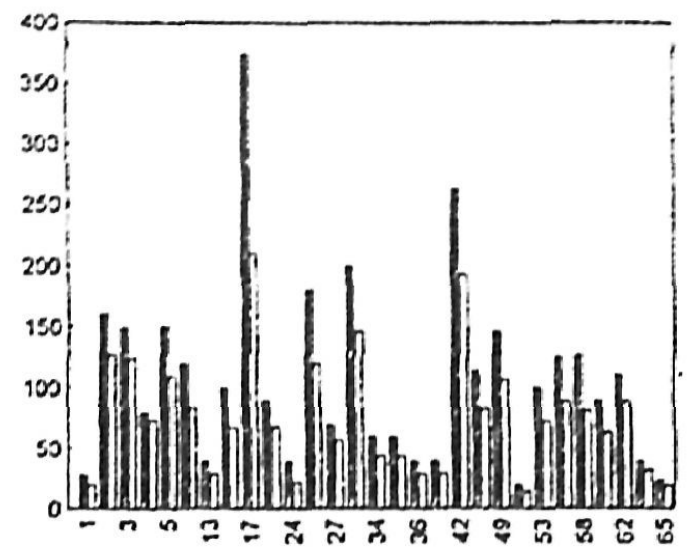

F2

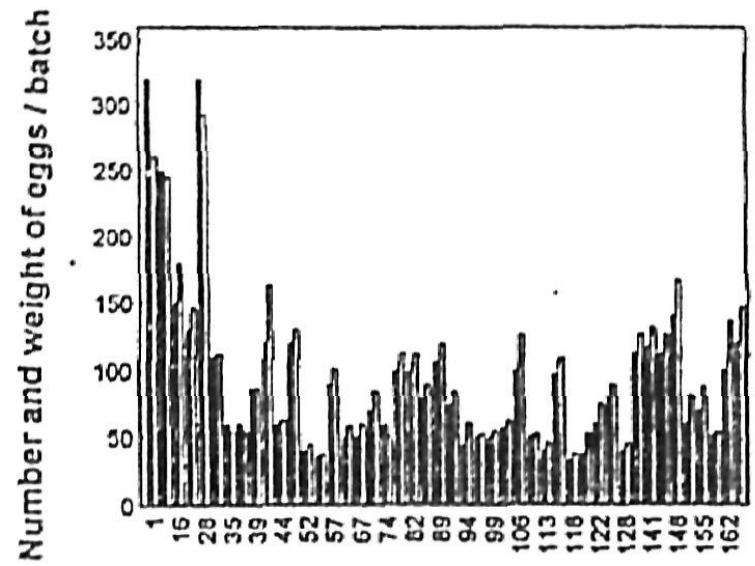

F3

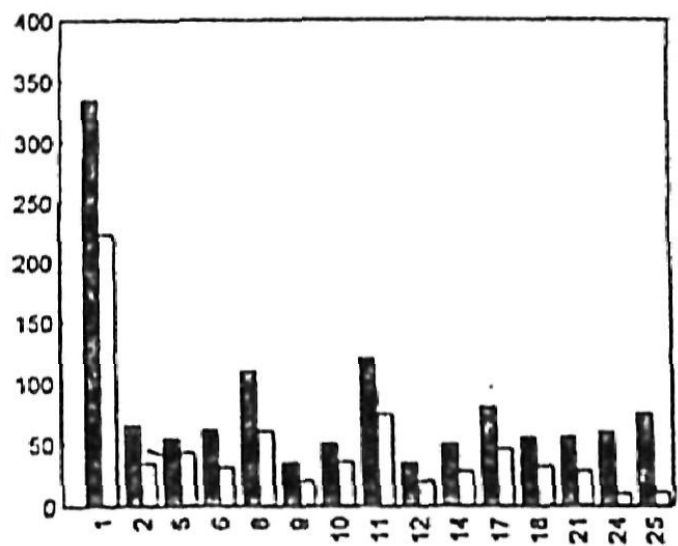

54

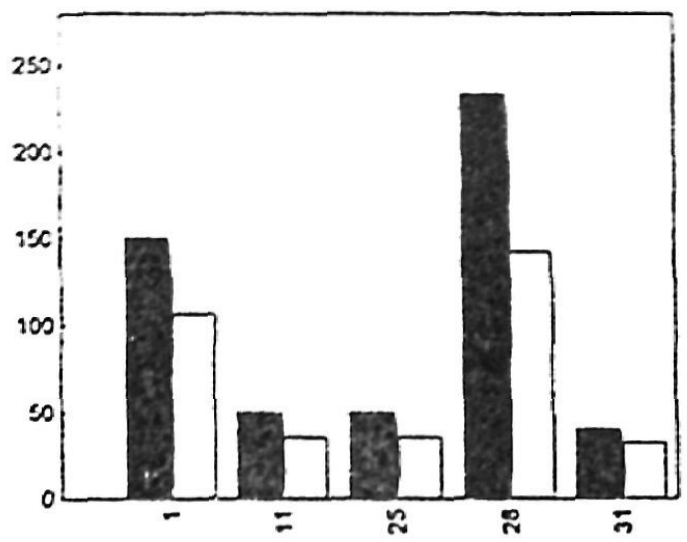

F5

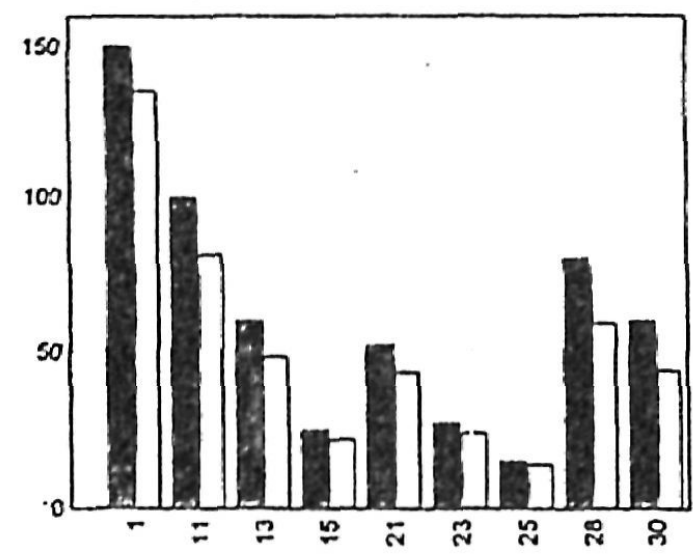

F6

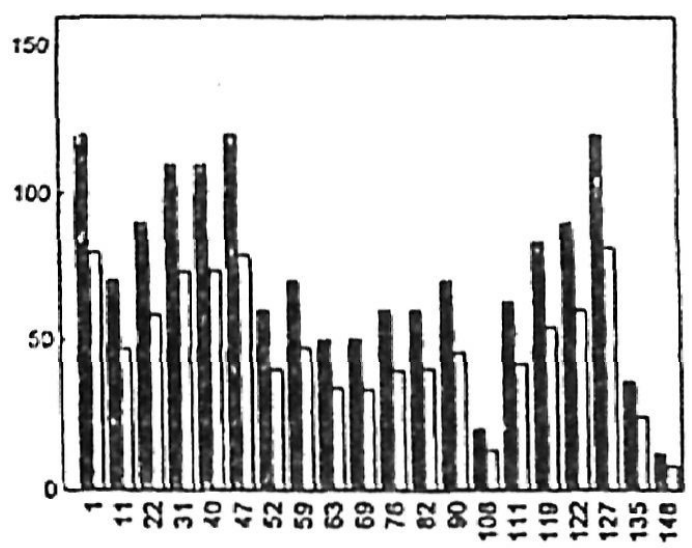

Spawning duration in days

Fig. 1. The spawning pattern in 6 females $S$. officinalis showing the number and the weight of laid batches and maximal spawning duration observed under laboratory conditions. 

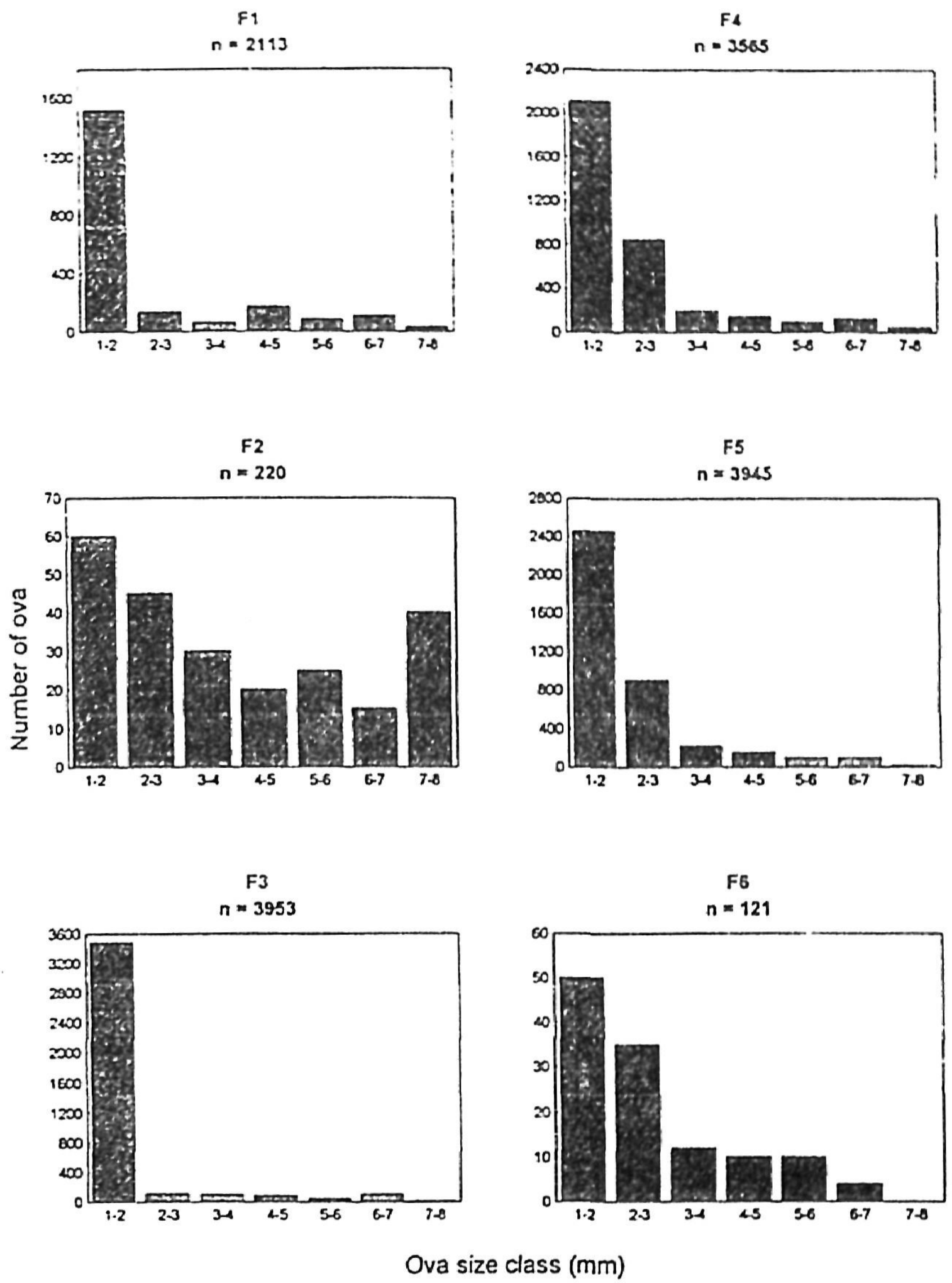

Fig. 2. Size frequency cistribution of ova recorded in the ovaries of 6 females $S$. officinalis 